\title{
When Intelligence is (Dys)Functional for Achieving Sales Performance
}

\author{
Willem J. Verbeke, Frank D. Belschak, Arnold B. Bakker \\ and Bart Dietz
}

\begin{tabular}{|l|l|}
\hline \multicolumn{2}{|l|}{ ERIM REPORT SERIES RESEARCHINMANAGMENT } \\
\hline ERIM Report Series reference number & ERS-2008-034-MKT \\
\hline Publication & June 2008 \\
\hline Number of pages & 51 \\
\hline Persistent paper URL & http://hdl.handle.net/1765/12633 \\
\hline Email address corresponding author & verbeke@few.eur.nl \\
\hline Address & Erasmus Research Institute of Management (ERIM) \\
& RSM Erasmus University / Erasmus School of Economics \\
& Erasmus Universiteit Rotterdam \\
& P.O.Box 1738 \\
& 3000 DR Rotterdam, The Netherlands \\
& Phone: $\quad+31104081182$ \\
& Fax: $\quad+31104089640$ \\
& Email: info@erim.eur.nl \\
& Internet: $\quad$ www.erim.eur.nl \\
\hline
\end{tabular}

Bibliographic data and classifications of all the ERIM reports are also available on the ERIM website:

www.erim.eur.nl 


\section{ERASMUS RESEARCH INSTITUTE OF MANAGEMENT}

\section{REPORT SERIES}

\section{RESEARCH IN MANAGEMENT}

\begin{tabular}{|l|l|}
\hline \multicolumn{2}{|l|}{ ABSTRACT AND KEYWORDS } \\
\hline Abstract & $\begin{array}{l}\text { Using two different samples of salespeople, the authors investigate how a combination of } \\
\text { general mental ability (GMA) and specific skills and capabilities (social competence and thinking } \\
\text { styles) allows salespeople to reach their sales goals. The study finds evidence for an interaction } \\
\text { between GMA and social competence. If combined with high social competence, high GMA } \\
\text { leads to highest sales performance; if combined with low social competence, high GMA leads to } \\
\text { lowest sales performance. In addition, interaction effects between GMA and a judicial thinking } \\
\text { style were found. Salespeople high on GMA have the most potential for attaining high levels of } \\
\text { sales performance when combined with specific skills; when lacking these skills they may } \\
\text { become the firm's worst performers. }\end{array}$ \\
\hline Free Keywords & sales, knowledge, knowledge based marketing, general mental ability, thinking styles \\
\hline Availability & $\begin{array}{l}\text { The ERIM Report Series is distributed through the following platforms: } \\
\text { Academic Repository at Erasmus University (DEAR), DEAR ERIM Series Portal } \\
\text { Social Science Research Network (SSRN), SSRN ERIM Series Webpage } \\
\text { Research Papers in Economics (REPEC), REPEC ERIM Series Webpage }\end{array}$ \\
\hline Classifications & $\begin{array}{l}\text { The electronic versions of the papers in the ERIM report Series contain bibliographic metadata } \\
\text { by the following classification systems: } \\
\text { Library of Congress Classification, (LCC) LCC Webpage } \\
\text { Journal of Economic Literature, (JEL), JEL Webpage } \\
\text { ACM Computing Classification System CCS Webpage } \\
\text { Inspec Classification scheme (ICS), ICS Webpage }\end{array}$ \\
\hline
\end{tabular}




\title{
When Intelligence is (Dys)Functional \\ for Achieving Sales Performance
}

\author{
Willem J. Verbeke ${ }^{1}$, \\ Frank D. Belschak ${ }^{2}$, \\ Arnold B. Bakker ${ }^{3}$, and \\ Bart Dietz ${ }^{4}$
}

(1) Willem J. Verbeke is Chair Professor in Sales and Account Management and Associate Professor in Knowledge Based Marketing in the Marketing Department, Erasmus University Rotterdam; P.O. Box 1738, 3000 DR Rotterdam, the Netherlands; phone: +31-10-4081308; fax: +31-10-4089169; email: verbeke@few.eur.nl

(2) Frank D. Belschak is Assistant Professor in the HRM - Organizational Behavior Department, University of Amsterdam Business School; Roetersstraat 11, 1018 WB Amsterdam, the Netherlands; phone: +31-20-5254027; fax: +31-20-5254182; email: f.d.belschak@uva.nl

(3) Arnold B. Bakker is Professor for Work and Organizational Psychology in the Department of Psychology, Erasmus University Rotterdam; P.O. Box 1738, 3000 DR Rotterdam, the Netherlands; phone: +31-10-4088853; fax: +31-10-4089009; email: bakker@fsw.eur.nl 
(4) Bart Dietz is Assistant Professor in the Organisation and Personnel Management Department, Erasmus University Rotterdam; P.O. Box 1738, 3000 DR Rotterdam, the Netherlands; phone: +31-10-4081949; fax: +31-10-4089015; email: bdietz@rsm.nl 


\title{
When Intelligence is (Dys)Functional
}

\section{For Achieving Sales Performance}

\begin{abstract}
Using two different samples of salespeople, the authors investigate how a combination of general mental ability (GMA) and specific skills and capabilities (social competence and thinking styles) allows salespeople to reach their sales goals. The study finds evidence for an interaction between GMA and social competence. If combined with high social competence, high GMA leads to highest sales performance; if combined with low social competence, high GMA leads to lowest sales performance. In addition, interaction effects between GMA and a judicial thinking style were found. Salespeople high on GMA have the most potential for attaining high levels of sales performance when combined with specific skills; when lacking these skills they may become the firm's worst performers.
\end{abstract}

\section{Keywords}

Sales, knowledge, knowledge based marketing, general mental ability, thinking styles 
As we are shifting to a knowledge intensive economy, salespeople sell knowledge based solutions to customers (Bettencourt et al. 2002). An essential part of selling knowledge based solutions is transferring knowledge to customers; salespeople therefore have to act as knowledge brokers (Sarvary 1999). During the sales interaction, both salesperson and customer play an active role and, together, co-create a solution (Vargo and Lusch 2004). This co-creation process takes place via conversations between the customer and the salesperson. For instance, salespeople share analogies and cases they earlier experienced with other customers to substantiate their solutions (Wierenga and van Bruggen 1997), and such cases help customers to (re-) frame and better understand their own needs, and conceive of possible solutions that fit those needs (Wotruba 1991). As a consequence, they may make smarter buying choices that - ideally - conform to the solutions and sales propositions of the salesperson (shaping) (e.g., Cross and Sproull 2004).

During this social construction of (knowledge based) solutions, salespeople's absorptive capacity is constantly challenged by customers (Cohen and Levinthal 1990). Intuitively, one may argue that cognitive ability, g-factor, or general mental ability (GMA) - which reflects a person's innate ability to think flexibly and reason abstractly (Sternberg 2003, p. 20) - should therefore play a prominent role. While this argument may seem straightforward, a closer look at the literature reveals a big debate around this issue. Many researchers argue that GMA is a predictor of job performance (e.g., Kuncell, Hezlett, and Ones 2004; Schmidt and Hunter 2004). Indeed, Hunter and Hunter (1984) show in their meta-analytic study that GMA predicts salespersons' performance particularly well. However, others report non-significant and close to zero 
correlations between GMA and job performance (e.g., Ceci and Liker 1986; Wagner and Sternberg 1985). Furthermore, Vinchur et al. (1998) and Schmitt et al. (1984) show only marginal correlations between GMA test scores and sales performance in their meta-analytic studies. Hence, the evidence regarding the relationship between GMA and job performance is mixed.

How can these conflicting findings be explained or integrated? Sujan, Weitz and Kumar (1994) as well as Cron et al. (2005) propose that traditional views of intelligence assessed through GMA tests are too narrow and should be replaced by a contextual perspective. Contextual intelligence refers to specific applications of one's intelligence which, in the context of personal selling, are for instance captured by the concepts of social competence and thinking styles (Sternberg 1997). As Sujan, Weitz, and Kumar (1994, p. 40) note, “contextual intelligence requires planning or mental preparing, being confident in one's ability to alter behavior, and making situationally appropriate adjustments to behavior." Consistently, we propose that GMA in and by itself does not predict job performance. Only in interaction with other aspects of intelligence it will have a significant predictive value in explaining job performance. Such a perspective is called the factorial view of intelligence. Metaphorically speaking, GMA "is to psychology as carbon is to chemistry" (Kuncel et al. 2004, p. 148) as it needs to be combined with specific skills, such as social competence, to show its effects. For instance, salespeople not only ought to possess a thorough understanding of the ideas behind the solutions/services they sell to customers (conceptual product space; see Rosa et al. 1999), they also should be able to present that knowledge in relevant and timely ways to customers so that they understand the service/product's value for their firm. Similarly, even though abilities such as GMA may be important 
for executing cognitively taxing tasks, this abstract ability has to be applied in concrete situations; being highly intelligent is not of any use for a salesperson, if s/he does not use this intelligence for specific purposes, e.g. to analyze the customer's situation, judge it, find an appropriate solution that satisfies the customer's needs, and communicate the solution in clear terms. As Sternberg (1997, p. 9) notes: "How people prefer to think might just be as important as how well they think."

The goal of this paper is to present and test the hypothesis that the relationship between GMA and job performance is moderated by other capacities and skills of the employee. Specifically, we will test our predictions in a sales setting. We present a factorial view on intelligence that incorporates two main dimensions, that is, GMA as a person's cognitive 'hardware' and social competence and thinking styles as the corresponding 'software'; we hypothesize that the effect of salespersons' GMA on their performance is contingent on the way they apply and use their cognitive 'software' during customer interactions. This hypothesis is tested in two different samples: In a first study, we investigate a sample of salespeople in one specific company who are selling advertising space to business customers. In a second study, we try to validate the findings of the first study and test their generalizability in a sample covering different industries and involving complex, knowledge intensive sales tasks.

\section{The Role of Knowledge in Sales}

Authors in sales (e.g., Wotruba 1991; Weitz and Bradford 1999) note that salespeople's role has changed from order taking to partnering/procreation. They distinguish between the provider/production stage (e.g., informing customers about the firm's offerings), the persuader stage (e.g., influencing customers by using hard-selling techniques), the problem- 
solver/marketing stage (e.g., influencing customers by practicing adaptive selling), and, finally, the procreation/partnering stage (e.g., co-producing business solutions with customers). As Vargo and Lush (2004) argue, according to a goods-centered dominant logic knowledge is treated largely as an exogenous factor whereas according to a service-centered dominant logic the skills and knowledge of the salesperson are key resources that render services or produce effects. Thus, knowledge is an endogenous factor in the knowledge based economy nowadays (Romer 1986). Vargo and Lush's distinction shows similarities with the sales stages as introduced by Wotruba (1991) and Weitz and Bradford (1999): while the first three stages may be seen as indicators of a goods-centered economy, the procreation/ partnering stage can be linked to a service-centered economy in which knowledge takes a prominent role in explaining exchanges between firms.

To understand and predict the performance of salespeople operating in the three first mentioned stages, researchers have primarily focused on salespeople's social skills and abilities while mostly ignoring the role of knowledge (such as a good understanding of the product space or the customer's industry, see Weitz and Bradford 1999). Prominent examples are boundary role theory which concentrates on how salespeople enact a set of activities or behaviors that are determined by the expectations and demands as communicated to the salesperson by his/her role set members (e.g., customers, managers) (Churchill, Ford, and Walker 1990) or adaptive selling, which refers to salespeople's ability to fashion different sales presentations for different (segments of) customers (Spiro and Weitz 1990). However, as we are entering the partnering/procreation stage salespeople determine the "buyer's problems or needs and the solutions to those problems or needs through active buyer-seller collaboration and then creating a market offering uniquely tailored to match those specific needs of each individual customer" (Wotruba 1991, p. 4). One would expect that researchers 
on sales should therefore focus on the acquisition and transfer of knowledge as a key variable. Yet, most of the research on sales in the partnering/procreation stage has focused on salespeople's ability to attain customers' trust (e.g., Morgan and Hunt 1994) and salespeople's ability to establish long term relationships with their customers (e.g., Anderson and Weitz 1992). These research questions, again, are mainly centered on social skills and neglect the role of knowledge and related cognitive abilities. In this study, we perceive salespeople as knowledge brokers (e.g., Sarvary 1999); consistently, we add a focus on cognitive abilities (that is, GMA) to the research agenda.

\section{GMA and its Relevance to the Sales Domain}

GMA refers to a person's aptitude to engage in complex tasks that require mental manipulation; this manipulation of information includes discerning similarities and inconsistencies, drawing inferences, and grasping new concepts, and it reflects intelligence in action (Gottfredson 1999). For instance, salespeople with a high GMA (as compared to a salespeople with a low GMA) are better able to learn to analyze and describe solutions related to e.g. logistics, distinguish between different features of technology-based solutions and/or products, or clearly express how their solutions differ from those of the competitors. However, GMA has created a large debate on its content validity, especially with the publication of Herrnstein and Murray's book 'The Bell Curve' in 1994. Some authors argue, for example, that the source of variation in IQ test scores is not cognitive, but instead arises from a "nexus of sociocognitive-affective factors determining individuals' relative preparedness for the demands of the GMA test" (Richardson 2002, p. 288). Critics on GMA also focus on the predictive validity of GMA test-results for job performance. They argue that GMA is merely one element in a factorial (modular) system of intelligence, which, in some views, consists of dozens of separate abilities that are needed in order to be successful in 
everyday life as well as in professional life (Mackintosh 1998; Neisser et al. 1996). Whereas the unitarian view argues that a general factor of intelligence (GMA) holds predictive validity for job performance, scholars taking a 'factorial approach' propose that a broader conception of intelligence (beyond GMA) that encompasses capabilities to cope with tasks of everyday life as well (i.e. software, such as social competence) results in better predictions of job performance (Carroll 1993; Sternberg et al. 1981). These conclusions have been supported by recent meta-analytic studies on the relationship between GMA and sales performance which show that GMA is mainly unrelated to (objective) sales performance (cf. Farrell and Hakstian 2001; Vinchur et al. 1998). As Bertua, Anderson, and Salgado (2005, p. 399) argue based on their data, "in the case of sales occupations, additional moderators may input on the validity of GMA tests." Research on GMA and job performance mostly investigated main effects of GMA in terms of additional explanatory value as compared to other factors such as personality (Barrick, Mount, and Strauss 1994). To date, only very few studies have investigated the interaction between GMA and other variables for predicting job performance in general (social competence: Ferris, Witt, and Hochwarter 2001; emotional intelligence: Cote and Miners 2006) or sales performance in particular (conscientiousness: Mount, Barrick, and Straus 1999; attributional style: Corr and Gray 1995).

Consistent with the factorial approach of intelligence, authors in sales argue that salespersons certainly need GMA as hardware, for instance, to understand the concepts behind the products and solutions they sell which may be complex. However, in addition, they need software such as specific skills that allow them to apply their GMA in effective ways and achieve high contextual intelligence (Cron et al. 2005; Sujan, Weitz, and Kumar 1994). In what follows, we will investigate the role of two specific types of software for the area of personal selling: social competence and thinking styles. Social competence is a crucial 
factor in selling because the personal interaction with individuals inside and outside the firm is a key aspect of sales. At the same time salespeople also act as knowledge brokers that have to manage different sources of knowledge (e.g., create new knowledge and help customers to integrate it into their existing knowledge; see Weitz and Bradford 1999); key activities of this knowledge brokering role are captured by the concept of thinking styles. To our knowledge, the effects of these variables (in particular in interaction with GMA) have not been investigated in a sales context to date.

\section{Social Competence}

Social competence is reflected in salespeople's interpersonal perceptiveness and the capacity to adjust their cognitive abilities to different situational demands to effectively influence and control (if needed) the response of others - for salespeople predominantly their customers (see Goleman 2006; Wright 2002). The concept of social competence resembles the construct of adaptive selling in the sales literature, i.e. salespersons' capacity to alter their sales approaches during or across customer interactions based on their perceptions of the nature of the selling situations (Spiro and Weitz 1990, p. 62). Yet, social competence is broader than adaptive selling: social competence allows salespeople to observe customers' behaviors within their own social context and interpret their intentions, goals, and needs. This is the basis for interacting in ways that are mutually beneficial to both the customer and the salesperson. Examples are giving thoughtful explanations of a product/service at the right time to the right person; or realizing and correctly understanding a customer's needs or unexpressed resistances so that the salesperson can properly explain what a solution means for the customer (perspective taking) (e.g., Zaltman 2003). Similarly, Gardner (1993) notes that people high in social skills not only are more successful in understanding and reading social interactions but also are more adept at evaluating others' opinions of their own capacities (Goleman 2006). 
Some authors use the term social intelligence here (e.g., Goleman 2006); however, as other researchers argue (e.g., Ferris, Witt, and Hochwarter 2001; Hogan and Shelton 1998), social competence may be a more appropriate label for the construct as it is not a stable personal ability (such as GMA) but rather learned through training and personal experiences.

\section{Thinking Styles}

Sternberg (1997) introduced the concept of thinking styles, defined as a person's preferred styles of using his/ her cognitive information processing abilities. Thinking styles are hence part of a person's software and do not correspond to cognitive abilities like GMA. Thinking styles reflect different ways in which people organize or govern themselves, and, in this sense, thinking styles refer to a theory of self-government (Sternberg 1997). Salespeople have to constantly learn from new and different sources in their sales job (customers, new products and technologies) (Vargo and Lush 2004) such that they acquire heterogeneous knowledge (Rodan and Galunic 1999) or strategic knowledge (Weitz and Bradford 1999). In this sense, Weitz and Bradford (1999, p. 249) note that that ideal candidates for a sales position in a partnering era are those that have worked in various functional areas of the firm and have experience with the buying firm to which they will be assigned as well as the buying firm's industry. Thinking styles reflect the way in which salespeople integrate and transfer that knowledge (e.g., by developing creative new solutions or by strictly following existing sales scripts). Indeed, thinking styles offer an interesting addition to analyze the relationship between intelligence and performance. As Sternberg (1997, p. 9) notes, thinking styles may be one powerful source of unexplained variation in job performance. Research has shown that, by adding thinking styles, the predictive validity of intelligence for academic

achievement could be increased (Grigorenko and Sternberg 1997; Zhang 2001). We therefore 
elaborate on three thinking styles that represent the functions of self-government: executive, judicial, and legislative (Sternberg 1997).

The executive style can be found among people who prefer to implement and carry out procedures. They like to follow rules, figure out which of already existing ways they should use to get things done, and prefer problems that are pre-fabricated or pre-structured. People characterized by an executive thinking style are particularly valuable for companies who have codified procedures for sales campaigns. People who like to evaluate rules and procedures score high on a judicial thinking style. They enjoy making judgments and prefer problems in which one has to analyze and evaluate existing ideas. An example may be a salesperson who tries to investigate the benefit of a certain solution s/he has used earlier in one industry for a new customer in another industry. A legislative style characterizes people who enjoy creating and formulating new solutions to problems (creative play). They prefer problems that are not prestructured or pre-fabricated but rather structure the problem themselves. Legislative salespeople hence try to be creative and find new solutions for customer problems, treating every customer as a new case that requires a new, unique solution.

\section{Hypotheses}

As we are moving to a knowledge economy, salespeople constantly have to assimilate and combine heterogeneous knowledge concerning solutions and markets (Rodan and Galunic 2004; Weitz and Bradford 1999). Consequently, they have to transfer that knowledge to customers and stimulate a learning process; customers then may frame their own business situation in new ways allowing salespersons and customers to jointly create a tailor made solution (Cross and Sproull 2004; Wotruba 1991). This knowledge based co-creation process requires elevated cognitive abilities (GMA) on the side of the salesperson, which have to be 
used in social situations and applied to specific practical problems. We therefore discuss possible interactions between a salesperson's GMA (hardware) and his/her different skills and abilities (software), specifically, social competence and the three thinking styles presented above.

\section{GMA and Social Competence}

Salespeople with a high social competence and a high GMA will be able to use the essential concepts of their solutions/services (GMA) (product spaces) and explain them in a language that fits the customer's concerns. They are able to not only break down complex aspects of the product (-space) in specific parts but also do so in ways that are relevant to a customer; they can ask the right questions to the customer such that they gain insights in customers' needs and problems. Such an understanding, in turn, allows them to develop and communicate tailor-made solutions that fit customers. They are also able to compare their solutions to the offers of their competitors and express them in clear terms such that customers can absorb the information, imagine what a proposed solution means for them, and (based on that) make informed choices. Specifically, in such situations customers feel psychological safety (e.g., Edmondson 1999) to structure and explore new ways to formulate their business problems and needs and to validate their own intuitions and observations (Cross and Sproull 2004). In addition, salespeople high in GMA and in social competence are able to provide arguments such that people at the customer's firm (e.g., other members of a buying centre) become enthusiastic about the presented solution, thus creating an emergent platform within the buying firm that is in favor of the salesperson and supports his/her sales propositions (e.g., Dawes, Lee, and Dowling 1998).

On the other hand, salespeople high on social competence but low on GMA may well be able to understand the social environment in which their customers operate but they may 
have a lower understanding of the concepts of their products/services (product space). They therefore may be less able to explain and/or codify clearly how their solutions fit the customer's needs, or how their offer differs from the ones of their competitors. Thus, even though they may have a good understanding of the customer's concerns or political coalitions within a buying centre, they will likely not be able to correctly analyze the customer's business and develop matching solutions that fit the long term goals of the customer. As a consequence, stimulating and fruitful conversations as the source of the co-creation of a successful business solution cannot emerge (Ferris, Witt, and Hochwarter 2001). Customers who are well-informed may even feel embarrassed to talk to salespersons that are acting socially competent but are unable to clearly express the concepts upon which their solutions are based. We therefore posit:

$\mathrm{H}_{1}$ : Social competence and GMA have a multiplicative impact on sales performance. Specifically, salespeople's GMA has a positive effect on their sales performance when combined with high social competence.

\section{GMA and Thinking Styles}

An executive thinking style is particularly conducive to handling problems that are wellstructured, and for which the organization has a set of rules or guidelines (Sternberg 1997; Zollo and Winter 2002). Salespeople who often use an executive thinking style but who score low on GMA may prefer to enter sales conversations while relying on sales presentations or elaborating solutions that have already been codified by colleagues (Hansen, Nohria, and Tierney 1999; Walker, Kapelianis, and Hutt 2005). Clear codification of solutions can improve the knowledge transfer to their customers (Kogut and Zander 1996) and may help customers to structure their own perceptions and intuitions (Leigh and Rethans 1984). Salespeople high on GMA and high on usage of executive thinking style, however, will 
perform relatively better using this codified knowledge and may have an advantage in these situations. For instance, despite the fact that salespeople may go through a scripted sales presentation (Leigh and Rethans 1984), salespeople have to respond to new and unanticipated questions, quickly analyzing the situation and finding an appropriate nonscripted answer or solution. Therefore, salespeople scoring high on both GMA and an executive thinking style will perform better. Hence, we hypothesize:

$\mathrm{H}_{2}$ : Executive thinking style and GMA have a multiplicative impact on sales performance. Specifically, salespeople's GMA has a positive effect on their sales performance when combined with a high use of an executive thinking style.

Salespeople are perceived as trusted advisors when they are capable to make relevant judgments and recommendations (based upon their experiences of similar cases for other customers) whether the products/services they sell fit the customer's state of affairs before making a concrete sales proposal. This allows the customer to reformulate his/her own business problems and also validate their own intuitions about potential solutions (Cross and Sproull 2004). This judging occurs via analogical reasoning: by thoroughly investigating the customer's situation by asking questions, salespeople are able to transfer useful wisdom to the customer from similar settings (source) they have experienced in the past or from earlier business cases stored in their memory (e.g., Gavetti, Levinthal, and Rivkin 2005; Wierenga and van Bruggen 1997; Zaltman 2003). Salespeople high on GMA who make strongly use of such a judicial thinking style will be able to better manage this analogical reasoning process: that is, they will better attend to meaningful or deep features of a customer's business problems and then look for similar patterns in cases they have experienced themselves or learned through colleagues or the business literature. This allows them to better isolate 
relevant cause and effect when evaluating similar business situations and to avoid analogies that may be used frequently yet only share superficial communalities between target (customer) and source (business case) (e.g., Holyoak and Thagard 1995; Gavetti and Rivkin 2005). The better the analogies used by the salesperson, the better customers can (re-) structure and (re-) frame their own business situation (and, as a consequence, their needs), and the better informed the choices they (can) make concerning the concrete solution of the salesperson; this, in turn, enhances the salesperson's status as a trusted advisor. Salespeople with low GMA, on the other hand, who strongly use a judicial thinking style, may enjoy making analogies but their analogies may be only superficial; that is, their low understanding of both the customer and the business case makes them prone to select only the most obvious features from both target and source leading to analogies that are not meaningful to customers (Gavetti and Rivkin 2005). Therefore we predict:

$\mathrm{H}_{3}$ : Judicial thinking style and GMA have a multiplicative impact on sales performance. Specifically, salespeople's GMA has a positive effect on their sales performance when combined with a high use of a judicial thinking style.

When salespeople engage in legislative thinking, they come up with new ideas and problem formulations through divergent thinking (sourcing and understanding of knowledge from a variety of situations) and convergent thinking (combining these ideas into a meaningful and relevant solution) (Perry-Smith and Shalley 2003). These new insights may allow salespeople and their customers to view their situation and problems from a new and fresh perspective ("thinking out of the box"). Yet, past meta-analyses on sales could not provide evidence for any significant effect of salespersons' creativity on their sales performance (e.g., Barrick and Mount 1991; see also Vinchur et al. 1998). Salespeople with high GMA who make 
strongly use of a legislative thinking style will likely source knowledge from a wide range of industries and disciplines such that complex and elaborated metaphors are created. Their high GMA and creative thinking styles may produce business solutions (creations) that only experts in the field understand (e.g., Moreau, Lehman, and Markman 2001). This ability to create new concepts may come as a handicap for the salesperson, because customers may see these new concepts as too far fetched, elaborated, and detailed (e.g., metaphors that have a clear scientific foundation) that exceeds their understanding. Consequently, customers cannot relate to it because these new concepts do not allow them to structure their own ideas and intuitions during encounters with the salesperson. In addition, very innovative ideas may provoke conflict and resistance in customers who are change-aversive (cf. Janssen, van de Vliert, and West 2004). Salespeople lower on GMA who engage in legislative thinking will likely develop concepts of lower complexity that may be easier to understand for customers and therefore more attractive and appealing. Thus, creative salespeople low on GMA may be perceived to be original within comprehensible limits. Therefore we propose:

$\mathrm{H}_{4}$ : Legislative thinking style and GMA have a multiplicative impact on sales performance. Specifically, salespeople's GMA has a negative effect on their sales performance when combined with a high use of a legislative thinking style.

\section{Study 1: Method}

\section{Procedure and Respondents}

A Dutch company selling print advertising provided its cooperation, and all its 171 salespeople participated in the study. Selling advertising space, on the one hand, requires a thorough knowledge of different advertisement media from the salesperson and involves communicating how within a rapid changing cross-media environment ads may reinforce the other messages of firms. On the other hand, media research companies provide support 
material for the salespeople in terms of tools that allow them to calculate and communicate concrete advertisement information to customers (e.g., terms like GRP's or the amount of exposure to a specific target audience are most commonly used); in this sense, the sales task is rather well-structured.

The questionnaire consisted of a test for measuring GMA, followed by several scales assessing participants' social competence and thinking styles. In addition, the company provided objective one-year sales performance figures (sales volumes) for each salesperson. Respondents filled in the questionnaire in groups of ten in the presence of one of the researchers. The sample can be described as follows: Two-thirds (67\%) of the participants were male; $25 \%$ were younger than 30 years, $40 \%$ between 30 and 40 years, $20 \%$ between 40 and 50 years, and $15 \%$ of the participants were older than 50 years. The majority of the salespeople had completed the equivalent of high school (31\%) or vocational training (34\%); $29 \%$ had graduated from college, and six percent held a university degree.

\section{Measures}

General Mental Ability (GMA) was measured with the Dutch version (Drenth 1965) of the 'Test of Non Verbal Reasoning' (R.B.H. \& Co. Inc., New York, USA). The test consists of forty exercises. Each exercise consists of ten figures. The first four figures are similar to each other in a certain respect, two of the remaining six figures fit with these four. The respondent has to find out which two out of the remaining six figures fit and mark them. The test also comprises a time component: the maximum time span available for finding the correct solutions is twenty minutes. The test is non-verbal in character and captures a person's ability to abstract, referring to the perception of relationships between abstract patterns between figures. Such ability corresponds to Spearman's g-factor and Thurstone's general factor (see Gottfredson 1999). 
Consistently, the test correlates significantly with the Raven Progressive Matrices (Drenth, van Wieringen, and Hoolwerf 2001).

Social competence was measured with Shafer's (1999) social competence scale. The instrument is based on Sternberg et al.'s (1981) social competence scale and consists of ten items, including "I deal effectively with people".

The three thinking styles were measured with three items (executive and judicial style) and four items (legislative style) taken from Sternberg (1997). Responses were given on a 7-point scale ranging from 'completely disagree' to 'completely agree'. Example items are: "I enjoy working on things that I can do by following directions" (executive style), "I like situations where I can compare and rate different ways of doing things" (judicial style), and "When facing a problem, I use my own ideas and strategies to solve it" (legislative style).

To test whether the three thinking styles can be differentiated empirically, we conducted a confirmatory factor analysis (CFA). Satisfactory model fits are indicated by non-significant chi-square tests, RMSEA values less than .08, and CFI and TLI greater than or equal to .90 (cf. Marsh, Balla, and Hau 1996). The results show that the proposed three-factor model provides a satisfactory fit to the data: $\chi^{2}(32)=62.70$, $\mathrm{CFI}=.92, \mathrm{TLI}=.90, \mathrm{GFI}=.93, \mathrm{RMSEA}=.07$. As all three thinking styles reflect a person's cognitive style of using his/her GMA, we also tested the fit of a one-factor model for the three thinking styles. The results indicate that such one-factor model provides an unsatisfactory, $\chi^{2}(35)=245.54, \mathrm{CFI}=.50, \mathrm{TLI}=.36, \mathrm{GFI}=.76, \mathrm{RMSEA}=.19$, and significantly worse fit than the three-factor model, $\Delta \chi^{2}(3)=182.84, p<.01$.

Sales performance was measured by using the net sales volumes (in Euros) of the participating salespersons in the year preceding this study. That is, the person's sales 
target was subtracted from his/her total sales volume to correct for prize and regional influences. In Study 1, we used the objective data as recorded by the company.

The descriptives, intercorrelations, and reliabilities of the measures described above are shown in Table 1.

[Insert Table 1 about here]

\section{Study 1: Results}

To test the hypotheses, we carried out a hierarchical linear regression analysis with sales performance as the dependent variable. In the first step, we included the three thinking styles, social competence, and GMA as the independent variables. In the second step, we added the interaction between GMA and social competence. In the final step, we included the interaction terms of GMA on the one hand and the three thinking styles on the other hand. Interaction terms were included in the analysis by adding the multiplicative products of the scores of the interacting variables (Aiken and West 1991). All variables in the analysis were centered around their means. The results of the regression analysis are summarized in Table 2.

[Insert Table 2 about here]

GMA, social competence, and the three thinking styles explained a total of six percent of the variance in salespersons' net sales volume. By adding the GMA * social competence interaction term, an additional two percent of the variance was explained, $F$-change $=4.35, p<.05$. When adding the interaction effects between GMA and thinking styles, another six percent of the variance in net sales volume was explained, $F$-change $=3.16, p<.05$, resulting in a final explained variance of fourteen percent.

Specifically, both an executive and a judicial thinking style had a significant main effect on salespeople's performance $(\beta=.26, p<.01$, and $\beta=-.19, p<.05$, 
respectively). Salespeople achieved a higher sales volume to the extent that they made use of an executive thinking style and avoided making use of a judicial thinking style. More relevant for the present study, a legislative thinking style in interaction with GMA produced a significant negative effect on performance $(\beta=-.23, p<.01)$, as hypothesized. The direction of the effect changes in the interaction between a judicial thinking style and GMA $(\beta=.19, p<.05)$, thus resulting in a significant positive effect on sales performance. In addition, and as predicted, the interaction between GMA and social competence had a significant positive impact on sales performance $(\beta=.24, p<$ $.01)$. The GMA * executive thinking style interaction was not significant $(\beta=-.05)$.

As recommended by several authors (e.g., Aiken and West 1991), we plotted the interaction effects for full interpretation of the results: We fixed the contingent variable (i.e., the software: social competence and thinking styles) at high versus low levels, with high versus low defined as one standard deviation below or above the mean score. The corresponding plots are shown in Figure 1. High and low values of GMA, as used in the figure below, were similarly defined as one standard deviation above or below the mean value.

\section{[Insert Figure 1 about here]}

Consistent with Hypothesis 1, Figure 1 (upper part) shows that GMA has a positive relationship with sales volume, but only when salespersons are high in social competence. Salespersons low in social competence, attain lower sales volume with increasing GMA. A similar pattern can be found for the interaction between a judicial thinking style and GMA (see middle part of Figure 1). GMA is positively related to sales performance for individuals who make strongly use of a judicial thinking style. In contrast, for salespeople who hardly use a judicial thinking style, GMA is negatively 
related to performance. This means that Hypothesis 3 is also substantiated. Finally, Figure 1 (lower part) also shows the opposite effect for GMA and a legislative thinking style: GMA is negatively (positively) related to sales volume when legislative thinking style is high (low), supporting Hypothesis 4. All slopes are significantly different from zero at the level of $p<.05$ with the exception of the regression of GMA on performance for a high judicial thinking style: here, the slope is only marginally significant $(p<.10)$.

\section{Study 1: Discussion}

The findings show that salespeople scoring high on both social competence and GMA achieved the highest sales performance. It seems that salespeople need both the ability

to systematically analyze and express the strengths of their own solutions (product space) and understand customers' needs and issues such that customers and salespeople both can co-create a solution. Interestingly, we found that salespeople who have a high score on GMA and a low score on social competence achieved the lowest sales performance. Imagine a salesperson that is good at analyzing, codifying, and expressing information concerning complex business issues, yet for instance is not aware that this information exceeds the ability (absorptive capacity) of the customer or is insensitive to the political issues involved in the buying decision process of the customer. This may make customers feel uncomfortable which, in turn, restrains them from reframing their own problems or issues causing their actual needs to remain unexpressed. Casciaro and Lobo (2005) label such salespeople as "competent jerks". In other cases, some customers may feel insulted that they cannot easily follow the arguments and propositions made by the high GMA salesperson, and -- as an excuse -- 
they may categorize the salesperson as abstract, aloof and even politically inappropriate, causing them to communicate in defensive ways.

We also found that salespeople low on judicial thinking style but high on GMA may be at a disadvantage: The higher the GMA of the salesperson, the more s/he may provide abstract and complex solutions to a business problem of the customer yet without placing them in a specific context. Consequently, it becomes difficult for the customer to understand the salesperson. Instead, the customer may need concrete and solid business cases or analogies to better imagine how solutions apply to their own business situations (cf. Wierenga and van Bruggen 1997; Cross and Sproull 2004), which salespeople low on judicial thinking yet high on GMA may not be able to provide.

Somehow surprisingly, we found that - regardless of the GMA of the salesperson - a low use of a judicial thinking style lead to a higher sales performance than a high use of a judicial thinking style. This finding can perhaps be explained by the nature of the specific sales task investigated in this study. Selling advertisement space, although it may require judging how a specific ad reinforces other media messages from a firm within a larger media space, may be conceived of as a well-structured task. Specifically, sales scripts were available, and salespeople only had a limited number of potential sales options. In this respect, successful salespeople did not (need to) refer to analogical reasoning and illustrative cases. This is consistent with two other findings: First, it may explain the finding that the application of an executive thinking style (i.e., following sales scripts) has a positive (main) effect on sales performance. Secondly, we also find that a combination of a high legislative thinking style in combination with a high GMA leads to the lowest sales performance: (too) creative salespeople seem to over-challenge their customers who may not appreciate (or even not understand) their associations at all, experience them as 'mental exercises', and/or feel 
that they are too far-fetched and away from their actual business problem at hand.

\section{Study 2}

As the findings in Study 1 were based on a sample that was entirely collected within one single company and covered one specific sales task, we investigated in a second study whether the findings would hold in a more diverse sales sample covering different industries as well as different, more complex sales tasks. In addition, we also included a number of control variables such as self-esteem or adaptive selling in this study to allow for a clearer interpretation of the findings.

\section{Procedure and Respondents}

In total, 50 Dutch firms were asked to participate in Study 2. The first contact with the companies was established through some of their employees (salespeople) who attended an executive education program in personal selling at the university. Thirtyone firms agreed to participate (response $=62 \%$ ), and they randomly asked up to four of their salespeople to participate in the study (total $\mathrm{N}=107$ ). The sample covered a wide range of different industries such as banking, consultancy, pharmaceutical industry, HRM services, and IT. Sales tasks were all business-to-business and involved the selling of rather complex business solutions (products and services). On an Internet site, salespeople both filled in the GMA test and the questions about their thinking styles and social competence. We also sent a short questionnaire to their sales manager who gave an evaluation of their sales performance. The sample in Study 2 can be described as follows: two thirds $(66 \%)$ of the participants were male; $33 \%$ were younger than 30 years, $46 \%$ between 30 and 40 years, sixteen percent between 40 and 50 years, and five percent of the participants were older than 50 years. Half of the 
salespeople had completed the equivalent of high school or vocational training; $35 \%$

had graduated from college, and fifteen percent held a university degree.

\section{Measures}

The measures used in Study 2 were identical to the ones used in Study 1, with one exception. Specifically, we used the same measures for the three thinking styles and social competence. To assess General Mental Ability (GMA) we used the short version of the 'Test of Non Verbal Reasoning' (Drenth 1965; R.B.H. \& Co. Inc., New York, USA), which includes twenty exercises and had to be accomplished within 10 minutes.

Unfortunately, it was not possible to get access to objective sales performance data as some companies were reluctant to give away this information to academic researchers for privacy as well as strategic reasons. We therefore asked the corresponding sales manager to evaluate the sales performance of his/her salespeople in the preceding year. Specifically we asked the managers to rate their salespeople's sales performance compared to the average salesperson in their company (on a scale from $1=$ 'way below average performance' to $7=$ 'way above average performance'); this was done to ensure a standardized approach that yields comparable results across industries and sales tasks. Furthermore, we explicitly instructed the managers on the evaluation form to base their ratings on the objective sales data of their salespeople. In our sales performance measure, we focused on sales ratings (that is, attainment of sales quotas) as we have used a similar objective performance measure in Study 1. Also, managers had objective data for their salespeople on this factor, and the measure should thus be less susceptible to individual, subjective rating biases of the manager.

Finally, we included a number of control variables in Study 2 to test whether sales performance was actually affected by the variables above or rather by other variables from the 
sales literature that may be related to them (see for example Boorom, Goolsby, and Ramsey 1998). Specifically, we included measures of adaptive selling (16 items taken from Spiro and Weitz 1990), self-esteem (10 items taken from Rosenberg 1965), (dispositional) optimism (6 items taken from Scheier, Carver, and Bridges 1994), and conscientiousness (5 items taken from John and Srivastava 1999). The reliabilities, descriptives, and correlations of all variables in Study 2 are presented in Table 3.

[Insert Table 3 about here]

\section{Study 2: Results}

To validate the findings of Study 1, we conducted a hierarchical linear regression analysis that is comparable with the analysis carried out in Study 1, with sales performance as the dependent variable. The main difference is that we now added adaptive selling, optimism, self-esteem, and conscientiousness as control variables in the analysis. Again, interaction terms were included in the analysis by adding the multiplicative products of the scores of the (mean-centered) interacting variables. The results of the regression analysis for Study 2 are summarized in Table 4.

[Insert Table 4 about here]

GMA, social competence, the three thinking styles, and the control variables explained a total of 18 percent of the variance in sales persons' sales volume. By adding the GMA * social competence interaction term, an additional seven percent of the variance was explained, $F$-change $=8.86, p<.01$. When adding the interaction effects between GMA and the three thinking styles, another five percent of the variance in sales volume was explained, $F$-change $=2.18, p<.05$, resulting in a final explained variance of thirty percent. Only conscientiousness had a significant main effect on salespeople's performance $(\beta=.25, p<.01)$. Consistent with Study 1 , a 
judicial thinking style in interaction with GMA produced a significant positive effect on performance $(\beta=.24, p<.05)$, as hypothesized in Hypothesis 3 . Next, as predicted and in line with Study 1, the interaction between GMA and social competence had a significant positive impact on sales performance $(\beta=.23, p<.05)$. Thus, Hypothesis 1 is supported. Finally, the interactions between GMA and one of the two other thinking styles were non-significant. Hypotheses 2 and 4 are therefore rejected.

As in Study 1, we plotted the two interaction effects for full interpretation of the results by fixing the contingent variable (i.e., social competence and thinking styles) at high versus low levels, with high versus low defined as one standard deviation below or above the mean score. High and low values for GMA, as used in Figure 2, were similarly defined as one standard deviation above or below the mean value.

\section{[Insert Figure 2 about here]}

Consistent with Hypothesis 1, GMA has a positive relationship with sales volume, but only when salespersons are high in social competence (see upper part of Figure 2). Salespersons low in social competence, attain lower sales volume with increasing GMA. A similar pattern can be found for the interaction between a judicial thinking style and GMA: GMA is positively related to sales performance for individuals who make strongly use of a judicial thinking style (see lower part of Figure 2). In contrast, for salespeople who hardly use a judicial thinking style, GMA is negatively related to performance. This means that Hypothesis 3 is also substantiated. All slopes of the regression lines are significantly different from zero at the level of $p<$ .05 with the exception of the regression of GMA on performance for a high judicial thinking style: similar to Study 1 , here the slope is only marginally significant at a level of $p<.10$. 


\section{Study 2: Discussion}

The results of the second study - drawing on a more diverse sample of salespeople involved in complex sales tasks - could replicate two of the findings of Study 1. First, salespeople high on social competence and high on GMA achieved the highest sales performance. Second, the interaction of a judicial thinking style and GMA had also a (marginally) significant (positive) effect on salespeople's performance. Specifically, salespeople high on GMA with a high usage of a judicial thinking style performed best. However, Hypothesis 2 and 4 were not substantiated. In what follows, we will further elaborate on the commonalities and differences of the findings of our two samples.

\section{General Discussion}

As salespeople mostly sell knowledge based solutions nowadays (e.g., Bettencourt et al. 2002; Vargo and Lush 2004), we suggested that salespeople should possess high GMA, which allows for quick learning and abstract thinking as key abilities. The findings of our studies indicate that salespeople high on GMA may indeed be at an advantage. To the extent that salespeople act as knowledge brokers, cognitive efforts are also required on the side of the customer: the salesperson and the customer cocreate a business solution by developing a joint understanding of the shared information and integrating it in a workable solution. Salespeople have to be able to manage this social-cognitive process to be able to successfully make viable sales propositions to customers. We proposed that salespeople's general mental ability -- the cognitive hardware -- interacts with specific skills or software (social competence and thinking styles), and argued that these interactions are able to predict sales

performance. Such a perspective draws upon researchers who argue for a contextual perspective on intelligence (e.g., Sujan, Weitz, and Kumar 1994; Cron et al. 2005). 
The results of our study indicate two main challenges that salespeople high on GMA face, if they want to successfully involve the customer in the solution cocreation process. First, salespeople have to be able to translate their solutions to customers and phrase the content of the solutions such that customers are capable of expressing their own business issues and experience psychological safety (Edmondson 1999). The more customers feel comfortable (safe) with the salesperson, the better they can (re-) frame their own business problems and are capable of absorbing how the developed solutions fit their needs. Salespeople's social competence in combination with their GMA facilitates this socio-cognitive learning process. Second, Axelrod and Cohen (1999) note that the more complex the solutions being sold, the more people rely on others to make informed choices. In a knowledge based economy customers seek to source different opinions and/or experiences with others. When salespeople are capable to better express the content of their business solutions, customers may (re-) formulate their business issues better (Cross and Sproull 2004). Salespersons' judicial thinking styles and GMA help them in this endeavor.

An interesting shared pattern of the findings of both studies is that the relationship between salespeople's GMA and their sales performance has a Janus face: while salespeople high on GMA became top performers when showing high degrees of social competence or a high judicial thinking style, they also became the worst performers when not applying the mentioned software sufficiently (i.e., only to a low extent). The main reason may be that selling knowledge involves the co-creation of knowledge as one of the main aspects: customers have to be able to structure their thoughts during sales interactions. Salespeople thus have to create a social comfort zone, which allows customers to express their needs, ideas, and objections without fear 
of embarrassment. In this sense, avoiding embarrassing customers by acting as a "competent jerk" may be one of the most important challenges for salespeople high on GMA to focus on (Casciaro and Lobo 2005).

Interestingly, the combination of a low GMA and a low social competence came with relatively high sales performance in Study 1. A possible explanation for this finding may be that, to participate in the knowledge co-creation process, customers need to feel psychological safety (Edmondson 1999). Salespeople characterized by low GMA and low social competence are likely to be perceived as neither intellectually threatening (not over-challenging customers' absorptive capacity) nor socially threatening (e.g., not engaging in micro-politics in buying centers). Especially in wellstructured sales situations like Study 1 in which the input of salespeople may be less needed, this may allow customers to comfortably explore and express their actual needs, which, in turn, facilitates a successful sales interaction.

Even though we could substantiate two of our hypotheses in both samples, two other of our initial hypotheses were not supported by the data. First, we did not find the interaction between GMA and an executive thinking style to significantly affect salespeople's performance. Rather, we found a significant main effect of an executive thinking style in Study 1 that indicates that GMA may play a less crucial role in wellstructured sales tasks. Here, it may be more efficient to develop sales scripts that salespeople should follow. In case of more complex sales tasks that ask for the absorption of new knowledge (Study 2) it may be more difficult to create valid sales script as every customer asks for a unique solution co-creation process that challenges the absorptive capacity of the salesperson (Cohen and Levinthal 1990). 
Second, we found the interaction between GMA and a legislative thinking style to be only related to sales performance in Study 1. Again, the specifics of the sales situation may play a role here. Selling advertising space (Study 1) is a relatively wellstructured task. Developing highly complex and creative business solutions may therefore be perceived as inadequate by customers and may be detrimental to salespeople's performance. This seemed not to be the case for more knowledge intensive firms and sales tasks (Study 2). Because of the high complexity of the task customers may not experience complex and creative solutions of the salesperson as inappropriate here.

In sum, the findings of our two studies illustrate that the interaction between salespeople's GMA as cognitive hardware and specific skills and capacities as software adds value to explaining sales performance and provides an interesting, fruitful avenue for further research. The studies also indicate that the GMAperformance relationship may be contingent on the type of sales task under investigation (well-structured versus complex).

So what lessons for practitioners can be learned from these findings?

- $\quad$ First, selection procedures for sales positions should encompass an IQ test, as depending on their GMA salespeople should use their software differently to improve their sales performance. As salespeople high on GMA formed the group of top performers, firms should hire salespeople with high GMA. Knowledge based economies are innovative, and the speed by which knowledge needs to be combined constantly increases. For that reason, smart conversations between salespeople and customers will become all the more important. 
- Second, in both samples salespeople high on GMA and low on social competence achieved the lowest sales performance. In terms of Casciaro and Lobo (2005) they may appear as 'competent jerks'; customers who interact with salespeople high on GMA may intuitively expect that that they also are socially competent - such a Halo effect of intelligence is a well-known phenomenon in social psychology. Therefore, salespeople should be assessed and tested for their social competence besides their GMA. As social competence can be learned, social competence training (especially for those salespeople high on GMA) is also advisable. From a methodological perspective, role-play training would seem most adequate to fit these needs.

- $\quad$ Third, for more complex sales tasks, using business cases proved to be a successful sales strategy. Salespeople (high on GMA) therefore should learn to listen to colleagues' business experiences and remember their own concrete business cases to be able to include them in stories that customers can relate to (Zaltman 2003). Salespeople should learn to share their stories (success/failure) with colleagues such that more people in the firm can use them. Similarly, salespeople could be encouraged to publish in trade journals or write internal "white papers" in which they express lessons learned.

\section{Further Research}

First, we would like to note that the degree of knowledge intensity varies across different sales functions. Weitz and Bradford (1999) distinguish different stages in selling with different degrees of sales task complexity (from provider stage up to procreator stage). Researchers should seek to explore different sales samples that reflect 
these different complexities of sales tasks to further specify how and when GMA interacts with other skills and capabilities.

Second, another prominent contextual skill that has received attention during the last years and might interact with GMA is emotional competence (e.g., Goleman 1998). Researchers note that the ability to regulate one's emotions is (e.g., Morris and Feldman 1996) and should be (e.g., Homburg and Stock 2004) an important part of work, especially for customer-boundary spanners such as salespeople. Emotional competence helps people to be aware of, regulate, and use their (and others') emotions successfully (Goleman 1998; Saarni 1999). Similar to the line of arguments put forward for social competence, one may expect that emotional competence also interacts with GMA for predicting salespeople's performance. Research by Cote and Miners (2006) found evidence that a high emotional competence may compensate for a lower GMA; we ask researchers to elaborate whether this finding also holds for salespeople. Similarly, research has found that the combination of integrity and GMA is more valid as selection criteria than relying on GMA alone (Robertson and Smith 2001). Future research should therefore also investigate integrity as a potential moderator of the GMA-performance relationship. 


\section{TABLE 1}

Means, Standard Deviations, Intercorrelations, and Reliabilities (Cronbach's alphas on diagonal) of the Variables in Study 1, N=171

\begin{tabular}{|c|c|c|c|c|c|c|c|c|}
\hline & Mean & $\mathrm{SD}$ & 1 & 2 & 3 & 4 & 5 & 6 \\
\hline 1 GMA & 49.32 & 12.75 & $(.87)$ & & & & & \\
\hline 2 Social competence & 5.62 & .68 & .03 & $(.76)$ & & & & \\
\hline 3 Legislative thinking style & 5.53 & .76 & -.01 & $.33 * *$ & $(.76)$ & & & \\
\hline 4 Executive thinking style & 4.66 & .95 & -.08 & .08 & $.34 * *$ & $(.74)$ & & \\
\hline 5 Judicial thinking style & 4.84 & .89 & -.02 & $.27 * *$ & $.19^{*}$ & $.30 * *$ & $(.70)$ & \\
\hline 6 Sales performance & -1554.17 & 25845.45 & $-.16^{*}$ & -.01 & .03 & .14 & -.08 & (n.a.) \\
\hline
\end{tabular}

$* p<.05 ; * * p<.01$ 


\section{TABLE 2}

Findings of the Regression Analysis in Study 1 (Standardized Regression Coefficients)

\begin{tabular}{|c|c|c|c|}
\hline \multirow[b]{2}{*}{ Independent variables } & \multicolumn{3}{|c|}{ Dependent variable: Sales volume } \\
\hline & Step 1 & Step 2 & Step 3 \\
\hline \multicolumn{4}{|l|}{ Main effects } \\
\hline GMA & -.15 & -.12 & -.06 \\
\hline Social competence & .02 & .01 & .01 \\
\hline Legislative thinking style & -.01 & -.01 & -.01 \\
\hline Executive thinking style & .17 & $.20^{*}$ & $.26^{* *}$ \\
\hline Judicial thinking style & -.15 & $-.15 *$ & $-.19 *$ \\
\hline \multicolumn{4}{|l|}{ Interaction effects } \\
\hline GMA x Social competence & & $.17^{*}$ & $.24 * *$ \\
\hline GMA x Legislative style & & & $-.23 * *$ \\
\hline GMA x Executive style & & & -.05 \\
\hline GMA x Judicial style & & & $.19^{*}$ \\
\hline$F$-value (p-level) & 1.80 (n.s.) & $2.26(p<.05)$ & $2.63(p<.05)$ \\
\hline$R^{2}$ & .06 & .08 & .14 \\
\hline
\end{tabular}




\section{TABLE 3}

Means, Standard Deviations, Intercorrelations, and Reliabilities (Cronbach's alphas on diagonal) of the Variables in Study 2, N=107

\begin{tabular}{|c|c|c|c|c|c|c|c|c|c|c|c|c|}
\hline & Mean & SD & 1 & 2 & 3 & 4 & 5 & 6 & 7 & 8 & 9 & 10 \\
\hline $1 \mathrm{GMA}$ & 30.24 & 4.89 & $(.84)$ & & & & & & & & & \\
\hline 2 Social competence & 5.65 & .63 & .04 & $(.71)$ & & & & & & & & \\
\hline 3 Legislative thinking style & 5.24 & .93 & .12 & $.30 * *$ & $(.72)$ & & & & & & & \\
\hline 4 Executive thinking style & 3.57 & 1.24 & .01 & -.11 & .01 & $(.69)$ & & & & & & \\
\hline 5 Judicial thinking style & 5.30 & 1.00 & .09 & $.19 *$ & $.19 *$ & -.15 & $(.76)$ & & & & & \\
\hline 6 Adaptive selling & 5.34 & .71 & -.03 & $.48 * *$ & $.26^{* *}$ & -.05 & $.29 * *$ & $(.85)$ & & & & \\
\hline 7 Conscientiousness & 5.36 & .59 & -.01 & $.19^{*}$ & $.20 *$ & -.02 & $.28 * *$ & $.28 * *$ & $(.82)$ & & & \\
\hline 8 Optimism & 5.42 & .79 & .07 & $.48 * *$ & $.35 * *$ & -.01 & .15 & $.55^{* *}$ & $.19 *$ & $(.80)$ & & \\
\hline 9 Self-esteem & 5.92 & .78 & -.09 & $.45^{* *}$ & $.19 *$ & -.18 & .10 & $.42 * *$ & $.29 * *$ & $.66 * *$ & $(.84)$ & \\
\hline 10 Sales performance & 4.57 & 1.06 & .01 & .11 & .18 & -.07 & .18 & .17 & $.28 * *$ & $.23 *$ & $.30 * *$ & (n.a.) \\
\hline
\end{tabular}

$* p<.05 ; * * p<.01$ 
TABLE 4

Findings of the Regression Analysis (Standardized Regression Coefficients) in Study 2

Dependent variable: Sales volume

Independent variables

Step 1

Step 2

Step 3

Control variables

Adaptive selling

$-.01$

$-.09$

$-.09$

Conscientiousness

$.20 *$

$.26 * *$

$.25 * *$

Optimism

.05

.10

.08

Self-esteem

$.25 *$

.20

.21

Main effects

GMA

$-.04$

$-.01$

$-.01$

Social competence

.12

$.24 *$

.17

Legislative thinking style

.08

.07

.07

Executive thinking style

$-.03$

$-.01$

$-.09$

Judicial thinking style

.11

.15

.11

Interaction effects

GMA x Social competence

$.32 * *$

$.24 *$

GMA x Legislative style

.07

GMA x Executive style

.15

GMA x Judicial style

$.24^{*}$

\begin{tabular}{lccc}
\hline$F$-value (p-level) & $1.90(p<.05)$ & $2.63(p<.01)$ & $2.51(p<.01)$ \\
\hline$R^{2}$ & .18 & .25 & .30 \\
\hline
\end{tabular}

$* p<.05 ; * * p<.01$ 
FIGURE 1

Interaction Effects of GMA on Sales Performance (Study 1)

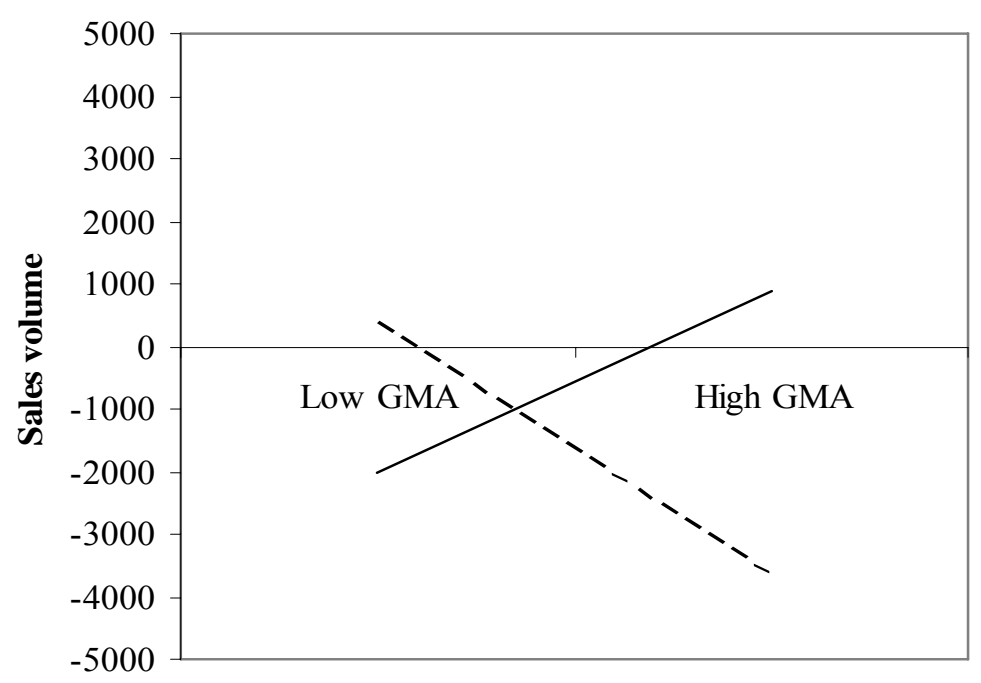

- - - - Low social competence

- High social competence

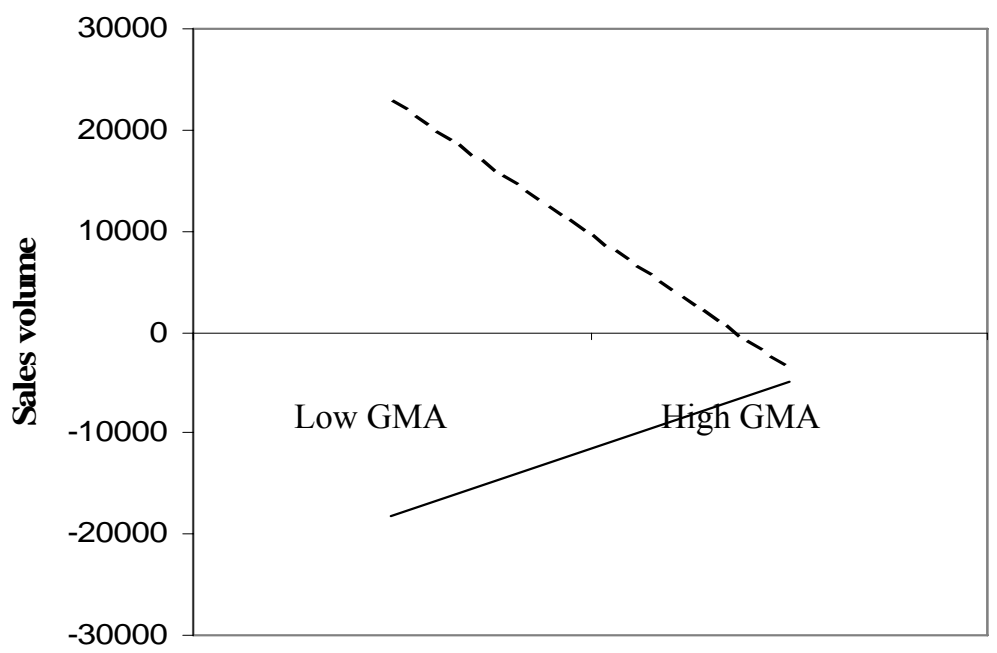

High judicial style

- - - - Low judicial style

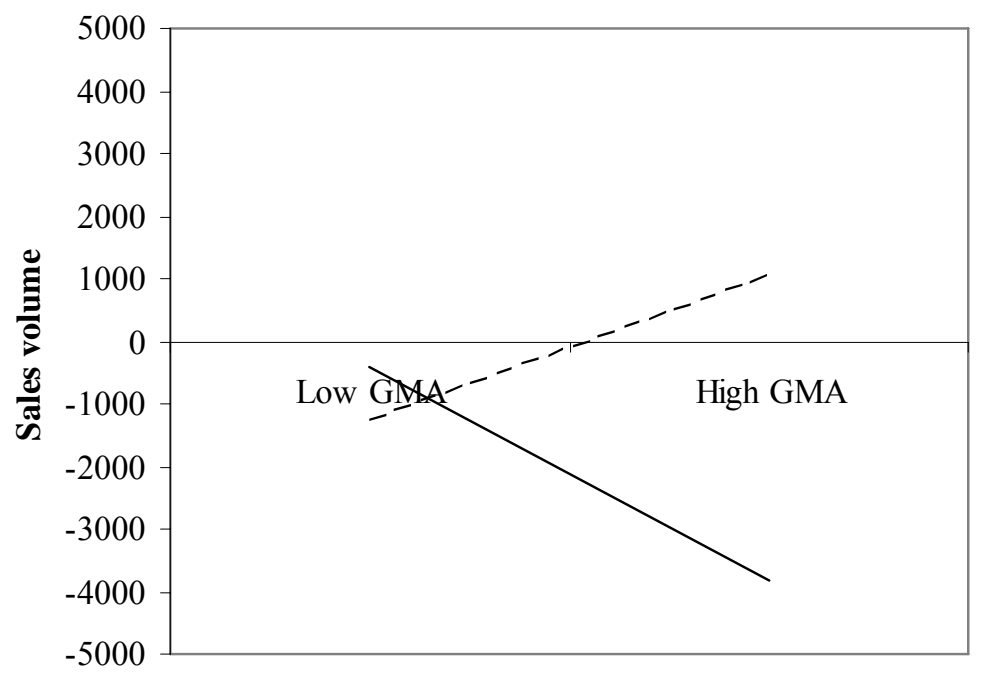

- - - Low legislative style

High legislative style 


\section{FIGURE 2}

Interaction Effects of GMA on Sales Performance (Study 2)

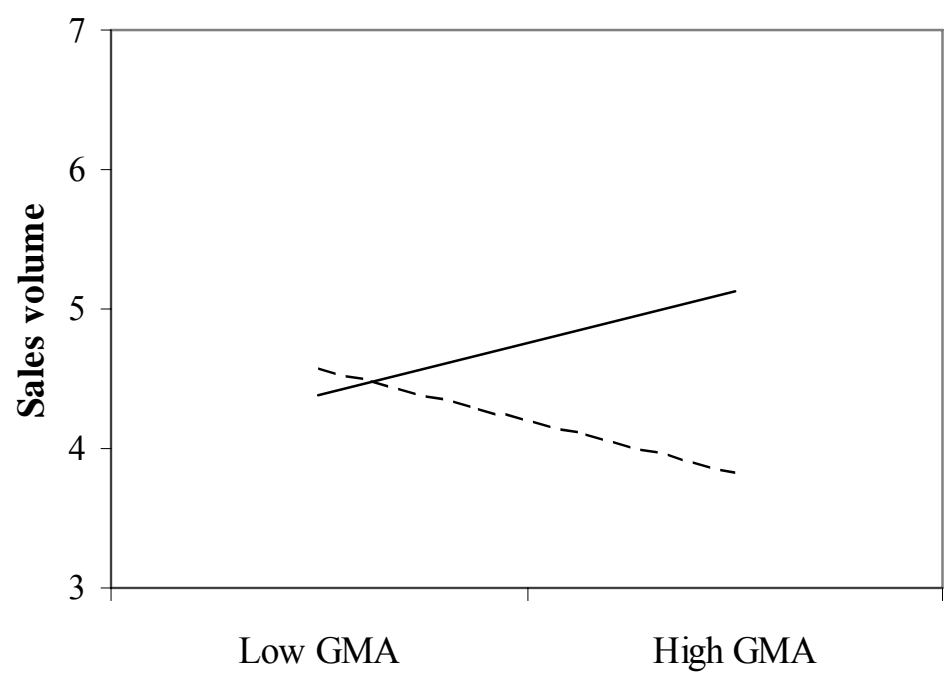

- - - - Low social competence - High social competence

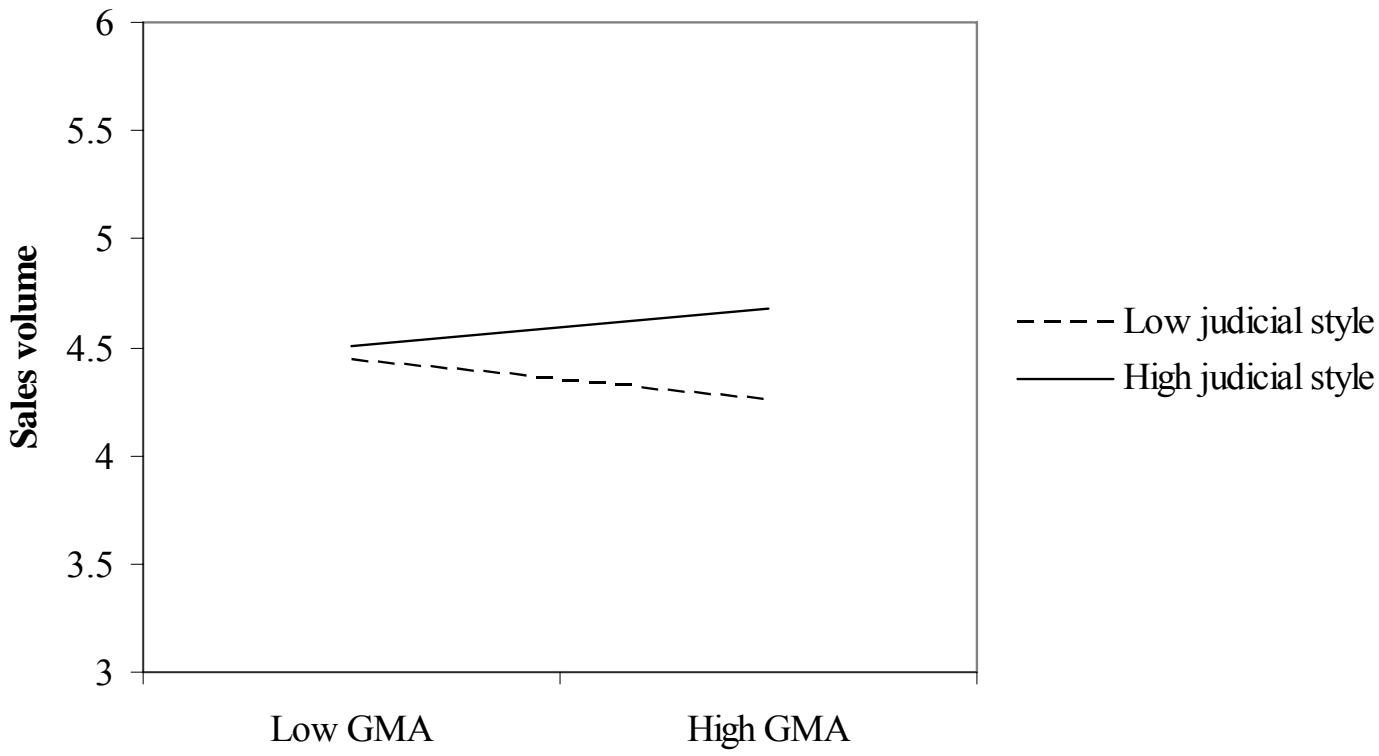




\section{References}

Aiken, Leona S. and Stephen G. West (1991), Multiple Regression: Testing and Interpreting Interactions. Newbury Park: Sage.

Anderson, Erin and Barton Weitz (1992), "The Use of Pledges to Build and Sustain Commitment in Distribution Channels," Journal of Marketing Research, 25

(February), 18-34.

Axelrod, Robert and Michael D. Cohen (1999), Harnessing Complexity. New York: The Free Press.

Barrick, Murray R. and Michael K. Mount (1991), "The Big Five Personality

Dimensions and Job Performance: A Meta-Analysis," Personnel Psychology, 44 (March), 1-26.

----, ----, and J. Perkins Strauss (1994), "Antecedents of Involuntary Turnover due to a Reduction in Force," Personnel Psychology, 47 (Autumn), 515-535.

Bertua, Cristina, Neil Anderson, and Jesus F. Salgado (2005), "The Predictive Validity of Cognitive Ability Tests: A UK Meta-Analysis," Journal of Occupational and Organizational Psychology, 78 (September), 387-409.

Bettencourt, Lance A., Amy L. Ostrom, Stephen W. Brown, \& Robert I. Roundtree (2002), "Client Co-Production in Knowledge-Intensive Business Services," California 
Management Review, 44 (Summer), 100-128.

Boorom, Michael, Jerry R. Goolsby, and Rosemary Ramsey (1998), "Relational Communication Traits and Their Effect on Adaptiveness and Sales Performance," Journal of the Academy of Marketing Science, 26 (Winter), 16-30.

Carroll, John B. (1993), Human Cognitive Abilities: A Survey of Factor-Analytic Studies. Cambridge, UK: Cambridge University.

Casciaro, Tiziana and Miguel Sousa Lobo (2005), "Competent Jerks, Lovable Fools, and the Formation of Social Networks," Harvard Business Review, 83 (June), 92-99.

Ceci, Stephen J. and Jeffrey K. Liker (1986), "A Day at the Races: A Study of IQ, Expertise, and Cognitive Complexity," Journal of Experimental Psychology, 115 (September), 255-266.

Churchill, Gilbert A., Neil M. Ford, and Orville C. Walker (1990), Sales Force Management. Homewood, Ill.: Richard D. Irwin Inc.

Cohen, Wesley M. and Daniel A. Levinthal (1990), "Absorptive Capacity: A New Perspective on Learning and Innovation," Administrative Science Quarterly, 35 (March), 128-152.

Corr, Philip J. and Jeffrey A. Gray (1995), "Attributional Style, Socialization and 
Cognitive Abilities as Predictors of Sales Success: A Predictive Validity Study," Personality and Individual Differences, 18 (February), 241-252.

Cote, Stephane and Christopher T.H. Miners (2006), "Emotional Intelligence, Cognitive Intelligence, and Job Performance," Administrative Science Quarterly, 51 (March), 1-28.

Cron, William L., Greg L. Marschall, Jagdip Singh, Rosann L. Spiro, and Harish Sujan (2005), "Salesperson Selection, Training, and Development: Trends, Implications, and Research Opportunities," Journal of Personal Selling and Sales Management, 25 (Spring), 123-136.

Cross, Rob and Lee Sproull (2004), "More Than an Answer: Information Relationships for Actionable Knowledge," Organization Science, 15 (July/August), 446-462.

Dawes, Philip L., Don Y. Lee, and Grahame R. Dowling (1998), "Information Control and Influence in Emergent Buying Centers," Journal of Marketing, 62 (July), 55-68.

Drenth, Pieter J.D. (1965), Test Voor Niet Verbale Abstractie: Handleiding. N.V. Amsterdam: Swets \& Zeitlinger.

----, P.W.C. van Wieringen, and Gerlof Hoolwerf (2001), Drenth Testserie Hoger Niveau: Handleiding. Lisse, The Netherlands: Swets \& Zeitlinger. 
Edmondson, Amy (1999), "Psychological Safety and Learning Behavior in Work Teams," Administrative Science Quarterly, 44 (June), 350-383.

Farrell, Seonaid and A. Ralph Hakstian (2001), "Improving Salesforce Performance: A Meta-Analytic Investigation of the Effectiveness and Utility of Personnel Selection Procedures and Training Interventions," Psychology \& Marketing, 18 (March), 281316.

Ferris, Gerald L., Witt, L. Alan, and Wayne A. Hochwarter (2001), "Interaction of Social Skill and General Mental Ability on Job Performance and Salary," Journal of Applied Psychology, 86 (December), 1075-1082.

Gardner, Howard (1993), Multiple Intelligences: The Theory in Practice. New York: Basic Books.

Gavetti, Giovanni and Jan W. Rivkin (2005), "What is a Good Analogy," Harvard Business Review, 83 (April), 54-63.

----, Daniel A. Levinthal, and Jan W. Rivkin (2005), "Strategy Making in Novel and Complex Worlds: The Power of Analogy," Strategic Management Journal, 26 (August), 691-712.

Goleman, Daniel (1998), Working With Emotional Intelligence. New York: Bantam. 
----(2006), Social Intelligence: The Hidden Impact of Relationships. New York: Bantam.

Gottfredson, Linda S. (1999), "The General Intelligence Factor," in The Scientific American Book of the Brain, The Editors of Scientific American, eds. Guilford, Connecticut: Lyons Press, 57-68.

Grigorenko, Elena L. and Robert J. Sternberg (1997), "Styles of Thinking, Abilities, and Academic Performance," Exceptional Children, 63 (3), 295-312.

Hansen, Morten T., Nitin Nohria, and Thomas Tierney (1999), "What's Your Strategy for Managing Knowledge," Harvard Business Review, 77 (March/April), 106-116.

Herrnstein, Richard J. and Charles A. Murray (1994), The Bell Curve. New York: The Free Press.

Hogan, Robert and Dana Shelton (1998), "A Socioanalytic Perspective on Job Performance," Human Performance, 11 (2-3), 129-144.

Holyoak, Keith J. and Paul Thagard (1995), Mental Leaps: Analogy in Creative Thought. Cambridge, MA: MIT.

Homburg, Christian and Ruth M. Stock (2004), "The Link Between Salespeople's Job Satisfaction and Customer Satisfaction in a Business-to-Business Context: A Dyadic Analysis," Journal of the Academy of Marketing Science, 32 (April), 144-158. 
Hunter, John E. and Ronda F. Hunter (1984), "Validity and Utility of Alternate Predictors of Job Performance," Psychological Bulletin, 96 (July), 72-98.

Janssen, Onne, Evert van de Vliert, and Michael West (2004), "The Bright and Dark Sides of Individual and Group Innovation: A Special issue Introduction," Journal of Organizational Behavior, 25 (March), 129-145.

John, Oliver P. and Sanjay Srivastava (1999), "The Big-Five Trait Taxonomy: History, Measurement, and Theoretical Perspectives, " in Handbook of Personality: Theory and Research, L. Pervin and Oliver P. John, eds. $2^{\text {nd }}$ edition. New York: Guilford, 102-138.

Kogut, Bruce and Udo Zander (1996), "What Firms Do? Coordination, Identity, and Learning," Organization Science, 7 (September-October), 502-518.

Kuncel, Nathan R., Sarah A. Heclett, and Deniz Ones (2004), "Academic Performance, Career Potential, Creativity, and Job Performance: Can One Construct Predict Them All?" Journal of Personality and Social Psychology, 86 (January), 148-161.

Leigh, Thomas W. and Arno J. Rethans (1984), "A Script-Theoretic Analysis of Industrial Purchasing Behavior," Journal of Marketing, 48 (Fall), 22-32.

Leonard, Dorothy and Walter Swap (1999), When Sparks Fly. Boston, MA: Harvard Business School. 
Mackintosh, Nicholas John (1998), IQ and Human Intelligence. Oxford: Blackwell.

Marsh, Herbert W., John R. Balla, and Kit-Tai Hau (1996), "An Evaluation of Incremental Fit Indices: A Clarification of Mathematical and Empirical Properties," in Advanced Structural Equation Modeling: Issues and Techniques, George A. Marcoulides and Randall E. Schumacker, eds. Mahwah, NJ: Erlbaum, 315-353.

Moreau, Page C., Donald R. Lehman, and Arthur B. Markman (2001), “Entrenched knowledge structure and consumer response to new products," Journal of Marketing Research, 38 (February), 14-29.

Morgan, Shelby D. and Robert M. Hunt (1994), "The Commitment Trust Theory of Relationship Marketing," Journal of Marketing, 58 (July), 20-38.

Morris, J. Andrew and Daniel C. Feldman (1996), "The Dimensions, Antecedents, and Consequences of Emotional Labor," Academy of Management Review, 21 (October), 9861010.

Mount, Michael K., Murray R. Barrick, and J. Perkins Strauss (1999), "The Joint Relationship of Conscientiousness and Ability with Performance: Test of the Interaction Hypothesis," Journal of Management, 25 (October), 707-721. 
Neisser, Ulric, Gwyneth Boodoo, Thomas J. Bouchard, A. Wade Boykin, Nathan Brody, Stephen J. Ceci, Diane F. Halpern, John C. Loehlin, Robert Perloff, Robert J. Sternberg, and Susana Urbina (1996), "Intelligence: Knowns and Unknowns," American Psychologist, 51 (February), 77-101.

Perry-Smith, Jill E. and Christina E. Shalley (2003), "The Social Side of Creativity: A Static and Dynamic Social Network Perspective," Academy of Management Review, 28 (January), 89-106.

Powell, Walter W. and Kaisa Snellman (2004), "The Knowledge Economy," Annual Review of Sociology, 30 (August), 199-220.

Richardson, Ken (2002), "What IQ Tests Test," Theory and Psychology, 12 (June), 283-314.

Robertson, Ivan T. and Mike Smith (2001), "Personnel Selection," Journal of Occupational and Organizational Psychology, 74 (November), 441-472.

Rodan, Simon and Charles Galunic (2004), "More than Networks: How Knowledge Heterogeneity Influences Managerial Performance and Innovativeness," Strategic Management Journal, 25 (June), 541-562.

Romer, Paul (1986), “Increasing Returns and Long-Run Growth,” Journal of Political Economy, 94 (October), 1002-1037. 
Rosa, Jose Antonia, Joseph F. Porac, Jelena Runser-Spanjol, and Michael S. Saxon (1999), "Sociocognitive dynamics in a product market," Journal of Marketing, 63 (October), 64-77.

Rosenberg, M. (1965), Society and Adolescent Self-Image. Princeton, NJ: Princeton.

Saarni, Carolyn (1999), The Development of Emotional Competence. New York: Guilford.

Sarvary, Miklos (1999), "Knowledge Management and the Competition in the Consulting Industry," California Management Review, 41 (Winter), 95-107.

Scheier, Michael F., Charles S. Carver, and Michael W. Bridges (1994),

"Distinguishing optimism from neuroticism (and trait anxiety, self-mastery, and selfesteem): A reevaluation of the Life Orientation Test, " Journal of Personality and Social Psychology, 67 (December), 1063-1078.

Schmidt, Frank L. and John Hunter (2004), "General Mental Ability in the World of Work: Occupational Attainment and Job Performance," Journal of Personality and Social Psychology, 86 (January), 162-173.

Schmitt, Neal, Richard Z. Gooding, Raymond A. Noe, and Michael Kirsch (1984), "Metaanalyses of Validity Studies Published Between 1964 and 1982 and the Investigation of Study Characteristics," Personnel Psychology, 37 (Fall), 407-422. 
Shafer, Alan B. (1999), "Relation of the Big Five and Factor V Subcomponents to Social Intelligence," European Journal of Personality, 13 (May-June), 225-240.

Spearman, Charles (1904), "General Intelligence, Objectively Determined and Measured," American Journal of Psychology, 15 (April), 201-293.

Spiro, Rosann L. and Barton A. Weitz (1990), "Adaptive Selling: Conceptualization, Measurement, and Nomological Validity," Journal of Marketing Research, 27 (February), 61-69.

Sternberg, Robert J. (1997), Thinking Styles. Cambridge, UK: Cambridge University.

----(2003), Wisdom, Intelligence, and Creativity Synthesized. Cambridge: Cambridge University.

----, Barbara E. Conway, Jerry L. Ketron, and Morty Bernstein (1981), "People’s Conceptions of Intelligence," Journal of Personality and Social Psychology, 41 (July), 37-55.

Sujan, Harish, Barton A. Weitz, and Nirmalya Kumar (1994), "Learning Orientation, Working Smart, and Effective Selling," Journal of Marketing, 58 (July), 39-52. 
Vargo, Stephen and Robert F. Lusch (2004), "Evolving to a New Dominant Logic for Marketing," Journal of Marketing, 68 (January), 1-17.

Vinchur, Andrew J., Jefferey S. Schippmann, Fred S. Switzer, and Philip L. Roth (1998), "A Meta-Analytic Review of Predictors of Job Performance for Salespeople," Journal of Applied Psychology, 83 (August), 586-597.

Wagner, Richard K. and Robert J. Sternberg (1985), "Practical Intelligence in RealWorld Pursuits: The Role of Tacit Knowledge," Journal of Personality and Social Psychology, 49 (August), 436-458.

Walker, Beth A., Dimitri Kapelianis, and Michael D. Hutt (2005), "Competitive Cognition," MIT Sloan Management Review, 46 (Summer), 10-12.

Weitz, Barton A. and Kevin D. Bradford (1999), "Personal Selling and Sales Management: A Relationship Marketing Perspective," Journal of the Academy of Marketing Science, 27 (Spring), 241-254.

Wierenga, Berend and Gerrit H. van Bruggen (1997), "The Integration of Marketing Problem-Solving Modes and Marketing Management Support Systems," Journal of Marketing, 61 (July), 21-37.

Wotruba, Thomas R. (1991), "The Evolution of Personal Selling," Journal of Personal Selling and Sales Management, 21 (Summer), 1-12. 
Wright, Peter (2002), "Marketplace Metacognition and Social Intelligence," Journal of Consumer Research, 28 (March), 677-682.

Zaltman, Gerald (2003), How Customers Think: Essential Insights into the Mind of the Market. Boston, MA: Harvard Business School.

Zhang, Li-Fang (2001), "Do Thinking Styles Contribute to Academic Achievement Beyond Self-Rated Abilities?" Journal of Psychology: Interdisciplinary and Applied, 135 (November), 621-637.

Zollo, Maurizio and Sidney G. Winter (2002), "Deliberate Learning and the Evolution of Dynamic Capabilities," Organization Science, 13 (May-June), 339-351. 


\section{Publications in the Report Series Research ${ }^{*}$ in Management}

\section{ERIM Research Program: "Marketing"}

2008

Experts' Stated Behavior

Youssef Boulaksil and Philip Hans Franses

ERS-2008-001-MKT

http://hdl.handle.net/1765/10900

The Value of Analogical Reasoning for the Design of Creative Sales Promotion Campaigns: A Case-Based Reasoning Approach

Niek A.P. Althuizen and Berend Wierenga

ERS-2008-006-MKT

http://hdl.handle.net/1765/11289

Shopping Context and Consumers' Mental Representation of Complex Shopping Trip Decision Problems Benedict G.C. Dellaert, Theo A. Arentze and Harry J.P. Timmermans ERS-2008-016-MKT

http://hdl.handle.net/1765/11812

Modeling the Effectiveness of Hourly Direct-Response Radio Commercials

Meltem Kiygi Calli, Marcel Weverbergh and Philip Hans Franses

ERS-2008-019-MKT

http://hdl.handle.net/1765/12242

Choosing Attribute Weights for Item Dissimilarity using Clikstream Data with an Application to a Product Catalog Map Martijn Kagie, Michiel van Wezel and Patrick J.F. Groenen

ERS-2008-024-MKT

http://hdl.handle.net/1765/12243

The Effect of Superstar Software on Hardware Sales in System Markets

Jeroen L.G. Binken and Stefan Stremersch

ERS-2008-025-MKT

http://hdl.handle.net/1765/12339

Sales Growth of New Pharmaceuticals Across the Globe: The Role of Regulatory Regimes

Stefan Stremersch and Aurélie Lemmens

ERS-2008-026-MKT

http://hdl.handle.net/1765/12340

When Intelligence is (Dys)Functional for Achieving Sales Performance

Willem J. Verbeke, Frank D. Belschak, Arnold B. Bakker, and Bart Dietz

ERS-2008-034-MKT

http://hdl.handle.net/1765/12633

Path Dependencies and the Long-term Effects of Routinized Marketing Decisions

Paul Farris, Willem J. Verbeke, Peter Dickson and Erjen van Nierop

ERS-2008-035-MKT

http://hdl.handle.net/1765/12634 
* A complete overview of the ERIM Report Series Research in Management: https://ep.eur.n//handle/1765/1

ERIM Research Programs:

LIS Business Processes, Logistics and Information Systems ORG Organizing for Performance

MKT Marketing

F\&A Finance and Accounting

STR Strategy and Entrepreneurship 